Article

\title{
Enhanced Photocatalytic Activity of Iron-Doped ZnO Nanowires for Water Purification
}

\author{
Yamina Ghozlane Habba, Martine Capochichi-Gnambodoe and Yamin Leprince-Wang * \\ ESYCOM, Université Paris-Est, UPEM, 5 Boulevard Descartes, F- 77420 Champs sur Marne, France; \\ Yamina-Ghozlane.Habba@u-pem.fr (Y.G.H.); martine.capo-chichi@u-pem.fr (M.C.-G.) \\ * Correspondence: yamin.leprince@u-pem.fr; Tel.: +33-1-6095-7276
}

Received: 2 October 2017; Accepted: 14 November 2017; Published: 17 November 2017

Featured Application: Water purification.

\begin{abstract}
In order to improve the photocatalytic efficiency of $\mathrm{ZnO}$ nanowires, iron-doped $\mathrm{ZnO}$ nanowires (ZnO:Fe NWs) were successfully synthesized. The morphology, optical properties and photocatalytic performance of $\mathrm{ZnO}: \mathrm{Fe} \mathrm{NWs}$ were studied by scanning electron microscopy (SEM), UV-Visible spectrophotometry and photoluminescence spectroscopy (PL), respectively. The SEM observations showed that the morphology of the $\mathrm{ZnO}$ NWs was not modified by iron doping, but the band gap was reduced from $3.29 \mathrm{eV}$ for $\mathrm{ZnO}$ NWs to $3.25 \mathrm{eV}$ for $\mathrm{ZnO}$ :Fe NWs. This band gap reduction allows the semiconductor to harvest more photons to excite more electrons in the valence band; subsequently, resulting in an improvement of the degradability of the understudied organic dyes: methylene blue (MB), methyl orange (MO), and acid red 14 (AR14). The photocatalytic study showed that the photo-degradation rate of the MB, MO, and AR14 was improved $9 \%, 20 \%$, and $5 \%$ respectively by $1 \%$ iron doping in the $\mathrm{ZnO} N W s$.
\end{abstract}

Keywords: $\mathrm{ZnO}$ nanowires; iron doping; water purification; photocatalysis

\section{Introduction}

In recent years, extensive fundamental research and development of the applied processes have been devoted to the polluted water treatment. Apart from the classical processes such as adsorption, filtration and sedimentation, the photocatalysis of semiconductor materials has attracted much attention as a promising solution for environmental problems. The photocatalysis process presents the advantage of decomposing and mineralizing a wide range of organic water pollutants into harmless products $\left(\mathrm{CO}_{2}, \mathrm{H}_{2} \mathrm{O}\right.$, etc.).

The water pollution caused by various dyes originating from textile, pharmaceutical and food-processing industries is becoming critical due to their use in large quantities. The World Health Organization (WHO) has set water quality at the top of its priority action list. In order to reduce the damage caused by organic dye pollution to the ecosystem and human health, the use of photocatalysts to degrade or to convert them into harmless chemical organic compounds in contaminated water has been extensively studied in recent years.

On the other hand, due to its very interesting physicochemical properties, $\mathrm{ZnO}$ has been largely studied for water purification in recent years [1,2]. Indeed, $\mathrm{ZnO}$ is a non-toxic and biocompatible semiconductor with high photosensitivity, and is relatively easy to synthesize at a low cost. Having the good physical and chemical stability, $\mathrm{ZnO}$ possesses a large band gap of $3.37 \mathrm{eV}$ and a high exciton binding energy of $60 \mathrm{meV}$. Thus, $\mathrm{ZnO}$ presents all environmentally friendly features for photocatalytic applications [3,4]. Generally, in the photocatalytic process, photo-generated holes which have a high oxidation power in the valence band (VB) and photo-generated electrons which have sufficient 
reduction power in the conduction band $(\mathrm{CB})$ are required for efficient photocatalytic reactions. However, the photocatalytic efficiency of $\mathrm{ZnO}$ is limited by the very short lifetime ( $0.322 \mathrm{~ns})$ of the photo-generated charge carriers (electron-hole pairs) in semiconductors due to the high probability of their recombination [5]. The other lack in the use of the undoped $\mathrm{ZnO}$ as photocatalyst is its wide band gap, thus the semiconductor can be activated only under ultraviolet (UV) light irradiation, which limits its practical applications. In consequence, to promote the photocatalytic performance of the semiconductor, it is not only necessary to increase the lifetime of charge carriers, but also to extend absorption edge up to the visible light region.

To expand the light absorption spectrum and to improve the solar energy utilization efficiency, many strategies have been exploited to modify the oxide semiconductor band gap structure in order to increase its sensitivity to visible light [6-9]. One of the effective methodologies to increase the photocatalytic activities of $\mathrm{ZnO}$, by increasing the visible-light absorption, is the doping of the $\mathrm{ZnO}$ nanostructure with transition-metals $[10,11]$, due to the band gap narrowing resulting from the creation of dopant energy levels below the CB [12,13]. This technique has, on the one hand, the advantage of effectively preventing the recombination of photo-generated electron-hole pairs; and on the other hand, can extend the photocatalysis' spectral range, leading to the improvement of the semiconductor photocatalytic activities. In spite of many transition metals having been reported in the literature, such as $\mathrm{Co}, \mathrm{Cr}, \mathrm{Ag}$, Sn etc., in our work, we focused on the iron doping of the $\mathrm{ZnO}$, because iron is a transition metal of very little negative impact on the environment. Nevertheless, the morphology of the photocatalyst plays an important role in the photocatalytic activity. The structure of the nanowire arrays has the advantage of a large specific surface with high surface to volume ratio which has prompted us to focus our research on the iron-doped $\mathrm{ZnO}$ nanowires ( $\mathrm{ZnO}: \mathrm{Fe} \mathrm{NWs).}$

The photocatalytic activity of the $\mathrm{ZnO}: \mathrm{Fe} \mathrm{NWs}$ for the organic pollutant degradation was investigated using three organic dyes, commonly used in textile, food-processing, and pharmaceutical industries, in aqueous solution: methylene blue (MB), methyl orange (MO), and azorubine (also called acid red 14-AR14). The ZnO NWs (undoped and Fe-doped), synthesized by low-cost hydrothermal method with a high aspect ratio, offer a large surface to volume ratio. The detailed degradation mechanism has been proposed for each dye in our previous work [14].

The morphology of both the un-doped and Fe-doped ZnO NWs was characterized using a scanning electron microscopy (FEG-SEM, NEON 40 ZEISS, Berkochen, Germany) operating at $10 \mathrm{kV}$ accelerating voltage. The photocatalysis process was followed by an UV-Vis spectrophotometer (Lambda 35, Perkin Elmer, Waltham, MA, USA) by periodically monitoring the absorption spectra of the organic dye solution during the photo-degradation process. Photoluminescence spectroscopy (PL) was used to characterize both undoped and Fe-doped $\mathrm{ZnO} N W s$ in order to understand the photocatalytic efficiency enhancement mechanism.

\section{Fe-Doped ZnO Nanowire Synthesis}

The synthesis of the Fe-doped nanowires was carried out by two-step hydrothermal method: The buffer layer consisting of $2 \mathrm{~g}$ of polyvinyl alcohol (PVA) and $0.25 \mathrm{~g}$ of zinc acetate dihydrate $\left(\mathrm{Zn}\left(\mathrm{CH}_{3} \mathrm{COO}\right)_{2} \cdot 2 \mathrm{H}_{2} \mathrm{O}\right)$ dissolved in water, was firstly spin-coated on the substrate as described in our previous work [14]; then the growth of ZnO:Fe NWs was carried out in the solution containing $25 \mathrm{mM}$ of zinc nitrate $\left(\mathrm{Zn}\left(\mathrm{NO}_{3}\right)_{2}\right), 12.5 \mathrm{mM}$ of Hexamethylenetetramine (HMTA), and $0.25 \mathrm{mM}$ of Iron (III) chloride $\left(\mathrm{FeCl}_{3}\right)$ at $95^{\circ} \mathrm{C}$. The process is similar to un-doped $\mathrm{ZnO}$ NWs growth [14], except for the addition of iron (III) to the growth solution.

Figure 1 shows a schema of the Fe-doped $\mathrm{ZnO}$ nanowire formation. This synthesis process is valid both for undoped and doped $\mathrm{ZnO}$ nanowire growth except the adding of $\mathrm{FeCl}_{3}$ in the growth solution for Fe-doping.

The plane-view and cross-section SEM images of the undoped and Fe-doped $\mathrm{ZnO}$ NWs (Figure 2), with the same growth time of $4 \mathrm{~h}$ and the same growth temperature of $95^{\circ} \mathrm{C}$, showed that the high aspect ratio $\mathrm{ZnO}$ NWs were obtained and the morphology of the nanowires was not modified by 
the iron doping. From the SEM plane-view images, by using Image software (Version 1.6.0, 2014) and by processing on ten different regions for each sample, we can estimate the nanowire density which was not significantly changed: $63 \pm 2$ nanowires $/ \mu \mathrm{m}^{2}$ for $\mathrm{ZnO}$ NWs vs. $61 \pm 2$ nanowires $/ \mu \mathrm{m}^{2}$ for ZnO:Fe NWs. Furthermore, the X-ray diffraction (XRD) measurements showed the typical ZnO Würtzite structure with preferred growth direction towards the $c$-axis both for undoped and Fe-doped $\mathrm{ZnO}$ nanowires (Figure 3).
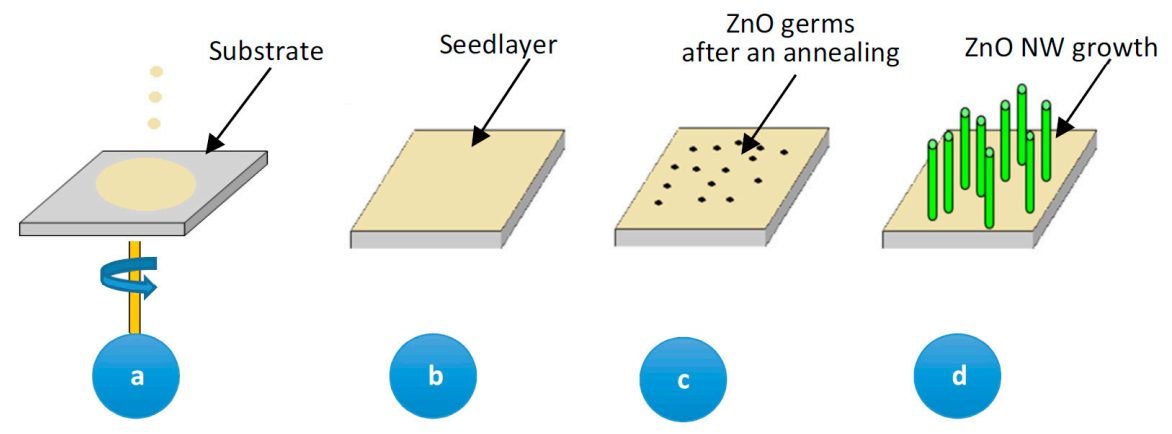

Figure 1. Schema of the $\mathrm{ZnO}$ nanowire formation: (a) Spin-coating of the seedlayer solution; (b) seedlayer based on the polyvinyl alcohol (PVA) and $\mathrm{Zn}\left(\mathrm{CH}_{3} \mathrm{COO}\right)_{2} \cdot 2 \mathrm{H}_{2} \mathrm{O}$; (c) $\mathrm{ZnO}$ nanocristallites formation after an annealing at $500{ }^{\circ} \mathrm{C}$ during $3 \mathrm{~h}$; (d) undoped and $\mathrm{Fe}$-doped $\mathrm{ZnO}$ nanowire ( $\mathrm{ZnO} \mathrm{NW}$ ) growth at $95{ }^{\circ} \mathrm{C}$ during $4 \mathrm{~h}$.

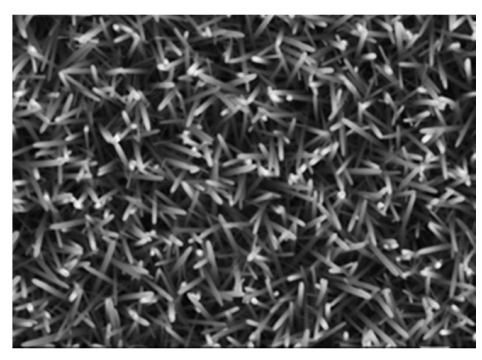

(a)

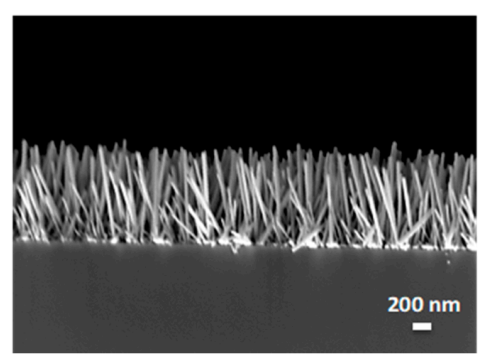

(c)

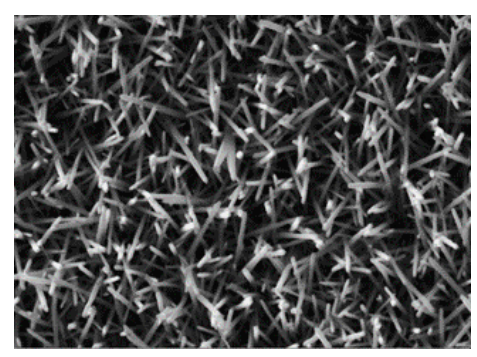

(b)

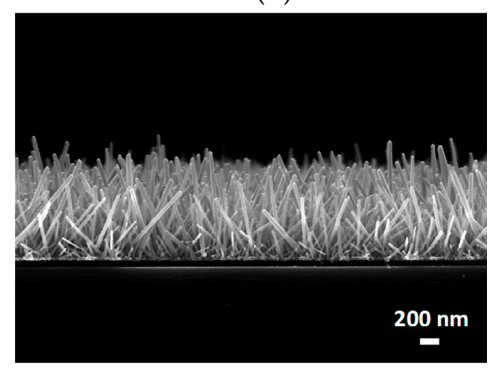

(d)

Figure 2. Plane-view and cross-section scanning electron microscopy (SEM) images of the undoped $\mathrm{ZnO}$ NWs $(\mathbf{a}, \mathbf{c})$ and Fe-doped $\mathrm{ZnO}$ NWs $(\mathbf{b}, \mathbf{d})$ obtained via hydrothermal method with growth time of $4 \mathrm{~h}$ at $95^{\circ} \mathrm{C}$.

UV-Visible spectroscopy analysis showed that the undoped and Fe-doped ZnO NWs exhibit a similar shape on the absorption spectra (Figure 4a). However, unlike undoped $\mathrm{ZnO}$ NWs showing a quasi-total transparency in the visible range, the UV-Visible spectrum of $\mathrm{ZnO}: \mathrm{Fe}$ NWs exhibits a significant absorption in the visible range (400-600 nm). By using the Tauc plot [15], a red shift (narrowing of band gap) is observed for Fe-doped $\mathrm{ZnO}$ (Figure $4 \mathrm{~b}$ ). This red shift is the common result in the transition-metal doped $\mathrm{ZnO}$, due to $\mathrm{sp}-\mathrm{d}$ exchange interactions between the $\mathrm{ZnO}$ band electrons 
and the localized " $\mathrm{d}$ " electrons of the transition-metal doped in the semiconductor matrix [16,17]. In this case, "s- $d$ " and " $p-d$ " exchange interactions lead to a negative correction to the CB edge and a positive correction to the VB edge of the $\mathrm{ZnO}$ matrix leading to a band gap narrowing. The band gap $\left(E_{\mathrm{g}}\right)$ values calculated by the Tauc's equation are 3.29 and $3.25 \mathrm{eV}$, respectively, for $\mathrm{ZnO} N W s$ and $\mathrm{ZnO}: \mathrm{Fe}$ NWs as shown in Figure $4 \mathrm{~b}$.

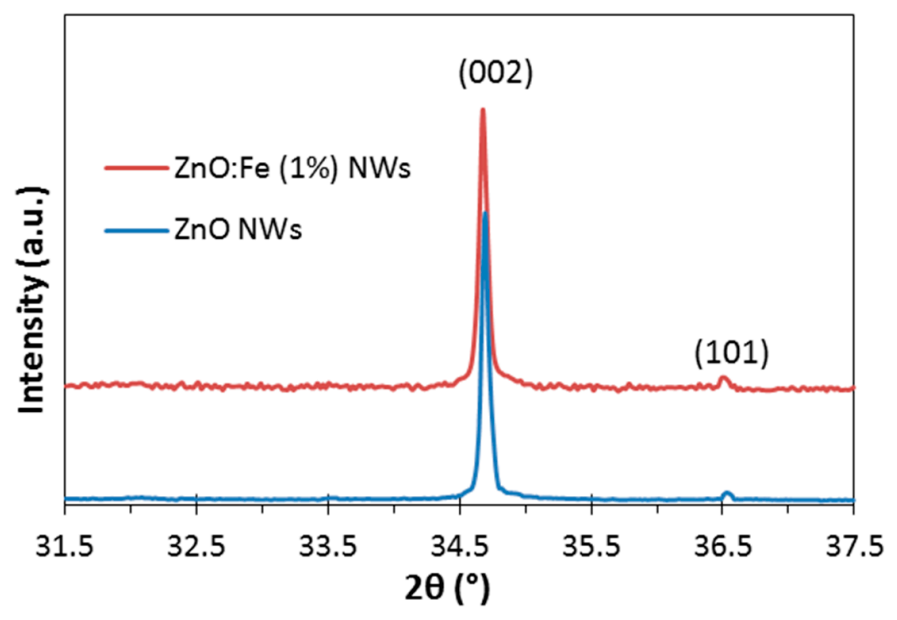

Figure 3. X-ray diffraction (XRD) spectra of the nanowire arrays obtained by hydrothermal method both for undoped $\mathrm{ZnO} \mathrm{NWs}$ and $1 \%$ Fe-doped $\mathrm{ZnO}$ NWs, respectively.

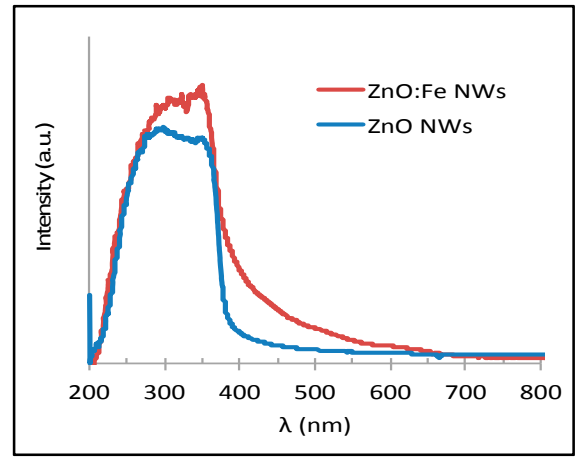

(a)

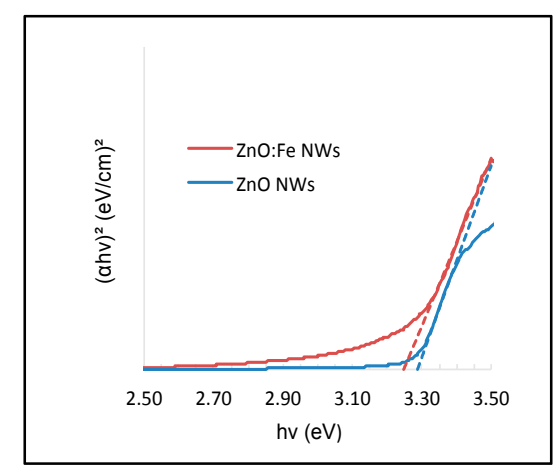

(b)

Figure 4. (a) UV-Visible absorption spectra of undoped and Fe-doped ZnO NWs; (b) Tauc plot showing a narrowing of $\mathrm{ZnO}$ NWs band gap after iron doping.

\section{Photocatalytic Activity Study and Discussion}

The principle of photocatalysis consists in using photon energy to activate the catalyst; this phenomenon is initiated by electron-hole pairs after a photo-excitation in the semiconductor. Indeed, when a photocatalyst is illuminated by light having photon energy larger than the semiconductor band gap, the electrons $\left(\mathrm{e}^{-}\right)$of the VB can pass to vacant orbitals of the $\mathrm{CB}$ leaving an equal number of holes $\left(h^{+}\right)$in the VB (Equation (1)).

If the free charges (electrons and holes) migrate to the surface of the semiconductor without recombining, then they can participate in various oxidation and reduction reactions with adsorbed species such as water, oxygen and other organic species by generating the hydroxyl radicals $\mathrm{OH}^{\bullet}$ which possess a high oxidation power. These successive reactions of oxidation and reduction of the photocatalytic mechanism can be described by the following equations:

$$
\mathrm{ZnO}+\mathrm{h} v \rightarrow \mathrm{ZnO}+\mathrm{e}^{-}+\mathrm{h}^{+}
$$




$$
\begin{gathered}
\mathrm{H}_{2} \mathrm{O}+\mathrm{h}_{\mathrm{VB}}^{+} \rightarrow \mathrm{OH}^{\bullet}+\mathrm{H}^{+} \\
\mathrm{OH}^{-}+\mathrm{h}_{\mathrm{VB}}^{+} \rightarrow \mathrm{OH}^{\bullet} \\
\mathrm{O}_{2}+\mathrm{e}_{\mathrm{BC}}^{-} \rightarrow \mathrm{O}_{2}^{\bullet-} \\
\mathrm{O}_{2}^{\bullet-}+\mathrm{H}^{+} \rightarrow \mathrm{HO}_{2}^{\bullet} \\
2 \mathrm{HO}_{2}^{\bullet} \rightarrow \mathrm{H}_{2} \mathrm{O}_{2}+\mathrm{O}_{2} \\
\mathrm{HO}_{2}^{\bullet}+\mathrm{O}_{2}^{\bullet-} \rightarrow \mathrm{HO}_{2}^{\bullet-}+\mathrm{O}_{2} \\
\mathrm{HO}_{2}^{\bullet-}+\mathrm{H}^{+} \rightarrow \mathrm{H}_{2} \mathrm{O}_{2} \\
\mathrm{H}_{2} \mathrm{O}_{2}+\mathrm{e}_{\mathrm{BC}}^{-} \rightarrow \mathrm{OH}^{\bullet}+\mathrm{OH}^{-} \\
\mathrm{H}_{2} \mathrm{O}_{2}+\mathrm{O}_{2}^{\bullet-} \rightarrow \mathrm{OH}^{\bullet}+\mathrm{OH}^{-}+\mathrm{O}_{2}
\end{gathered}
$$

Finally, these $\mathrm{OH}^{\bullet}$ radicals having a strong oxidation power, can lead to a partial or complete mineralization of the organic substances (such as the dyes, for example) in the waste water, forming non-toxic products such as $\mathrm{CO}_{2}$ and $\mathrm{H}_{2} \mathrm{O}$, as shown in Equation (11).

$$
\mathrm{OH}^{\bullet}+\text { Pollutants } \rightarrow \text { Intermediary Products } \rightarrow \mathrm{CO}_{2}, \mathrm{H}_{2} \mathrm{O} \ldots
$$

In our study, the photocatalytic efficiency of Fe-doped $\mathrm{ZnO}$ nanowires was studied on three organic dyes (MB, MO, and AR14) which are the main components of textile, food-processing and pharmaceutical industrial waste materials. The study of their photo-degradation was carried out under a combined Mercury-Xenon UV-Visible combined lamp (HAMAMATSU-LC8) (Hamamatsu Photonics, Shizuoka, Japan) with main irradiation wavelength of $365 \mathrm{~nm}$ and an irradiation intensity of $4500 \mathrm{~mW} / \mathrm{cm}^{2}$ under a normal incidence on the out level of the lamp. The sample of ZnO:Fe NWs grown on the Si substrate, has an effective surface area of about $1 \mathrm{~cm}^{2}$. The initial concentration of aqueous solution of each organic dye was $10 \mu \mathrm{M}$. The sample of $\mathrm{ZnO}$ NWs was placed at the bottom of the container with a fixed dye solution volume of $50 \mathrm{~mL}$. The distance between the UV lamp and the sample surface was maintained at $10 \mathrm{~cm}$ for all photocatalysis experiments as shown in our previous work [14]. It is worth noting that during the photocatalytic reaction, there is no stirring in the solution for this study.

The evolution of the photocatalytic reaction was followed by an UV-Vis spectrophotometer, by periodically recording the absorption spectra in order to monitor the concentration change of the residual organic dye in the solution. The residual dye content in the solution was determined by a degradation percentage defined by the following relation:

$$
X(\% \text { Degradation })=\left(\frac{A_{0}-A_{t}}{A_{0}}\right) \times 100 \%
$$

where $A_{0}$ is the initial dye absorbance, at the maximum absorption wavelength of the dye, before illumination and $A_{t}$ is the dye absorbance at time $t$.

The characteristic absorption peaks in UV-Vis spectroscopy corresponding to the molecules MB, $\mathrm{MO}$ and AR14 are localized at 665, 464 and $515 \mathrm{~nm}$, respectively. Photo-degradation spectra with undoped $\mathrm{ZnO}$ NWs and without $\mathrm{ZnO}$ NWs were systematically recorded in parallel for each dye in order to compare with Fe-doped ZnO NWs.

Figure 5 summarizes the spectra of photo-degradation for undoped and iron-doped $\mathrm{ZnO}$ NWs for the three understudied organic dyes. One can note that the absorption peak for each dye decreases progressively in intensity with the light illumination time, indicating a decrease in the dye concentration in the solution. It worth noting that the photo-degradation time of $180 \mathrm{~min}$ is not a time limit; it is more a pre-fixed time for all our photo-degradation process in this study. 
Figure 6 shows a comparison of the photo-degradation rate evolution of the three dye solutions in the presence of $\mathrm{ZnO}: \mathrm{Fe}$ NWs, $\mathrm{ZnO}$ NWs and without $\mathrm{ZnO}$ under a UV lamp exposure for $180 \mathrm{~min}$.

According to the obtained results, one can note that the photo-degradation rate of the various dyes (MB, MO and AR14) increases with light irradiation time in the presence of the photocatalyst (undoped and doped $\mathrm{ZnO}$ NWS). The photocatalytic activities of $\mathrm{ZnO}$ :Fe NWs (with $1 \% \mathrm{Fe}$-doping) showed to be more efficient compared to those of $\mathrm{ZnO}$ NWs. Using the $\mathrm{ZnO}: \mathrm{Fe} \mathrm{NWs}$, the photo-degradation rate of $\mathrm{MO}$ was improved by $20 \%$ compared to a photo-degradation rate with undoped $\mathrm{ZnO} N W s$, going from $49 \%$ to $69 \%$ after $3 \mathrm{~h}$ of illumination. It should be emphasized that due to the high energy of $4.33 \mathrm{eV}$ of the main $\mathrm{N}=\mathrm{N}$ bond in MO molecule, $\mathrm{MO}$ is one of the most difficult dyes to degrade compared to the others dyes such as MB and AR14. Although the AR14 dye also contains the $\mathrm{N}=\mathrm{N}$ bond, the attracting effect of the $\mathrm{OH}^{\bullet}$ radicals on the aromatic ring creates a deficit on the carbon atom in the $\mathrm{C}-\mathrm{N}=$ bond, which further weakens the $\mathrm{C}-\mathrm{N}$ bond. The photo-degradation mechanism has been proposed for each dye in our previous work [14] under the same experimental conditions. Iron doping also improved the photocatalytic efficiency for the MB and AR14 depollution, their photo-degradation rate increases from $86 \%$ to $95 \%$ for MB and from $93 \%$ to $98 \%$ for AR14. Moreover, since the nanowire density is similar (Figure 2) in two cases, thus, we can conclude that the Fe-doped ZnO NWs have greater photocatalytic activities than the undoped $\mathrm{ZnO}$ NWs.

$$
\text { Dyes }
$$

Photocatalysis with ZnO NWs
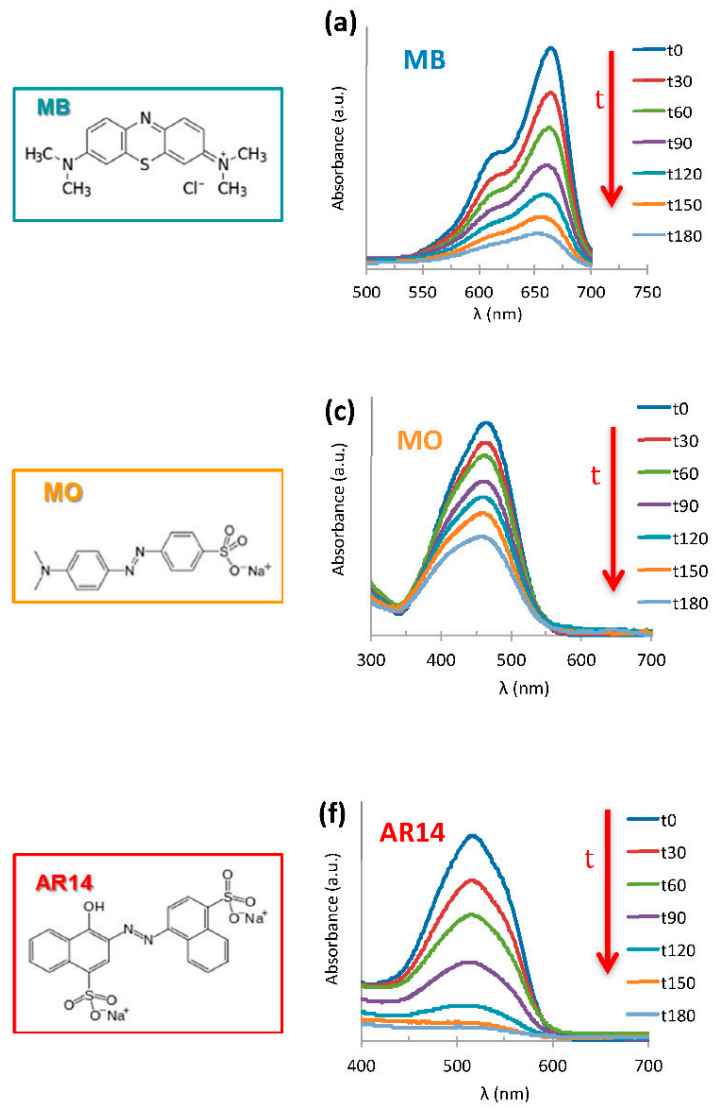
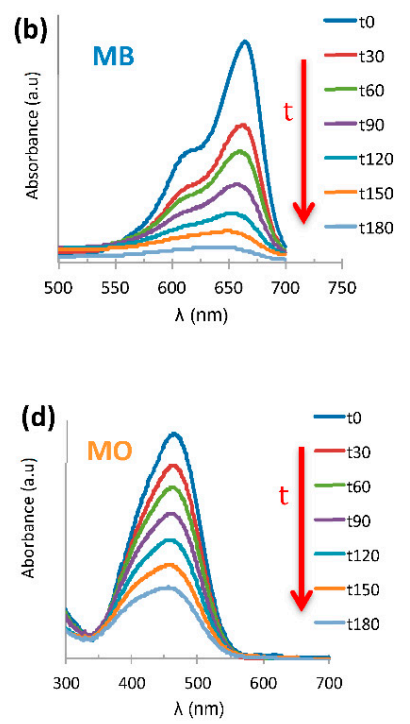

Photocatalysis with ZnO:Fe NWs

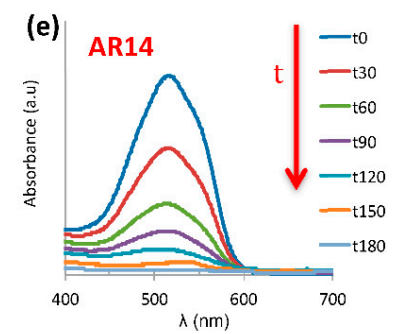

Figure 5. Evolution of $\mathrm{ZnO}$ NWs photocatalysis UV-Vis absorption spectra of $\mathrm{MB}(\mathbf{a})$; $\mathrm{MO}$ (c) and AR14 (e); and of ZnO:Fe NWs photocatalysis UV-Vis absorption spectra of MB (b); MO (d) and AR14 (f).

Photocatalytic activity of undoped $\mathrm{ZnO}$ is generally attributed to two kinds of states: (1) The donor states formed by the large number of defect sites such as oxygen vacancies and interstitial zinc atoms; (2) the acceptor states formed by zinc vacancies and interstitial oxygen atoms. Dhiman et al. [17] 
assume that the interfacial electron transfer takes place predominantly between these donor states (oxygen vacancies and interstitial $\mathrm{Zn}$ atom) and Methylene Blue. Being a cationic dye, Methylene Blue acquires electrons from excited donor states and decomposes. This faster degradation rate of Methylene Blue under visible light irradiation using Fe-doped $\mathrm{ZnO}$ is attributed to the increase in defect sites caused by Fe-doping, leading to an enhanced optical absorption in the visible region.

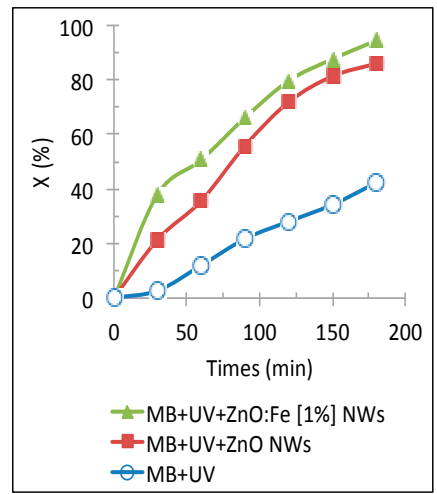

(a)

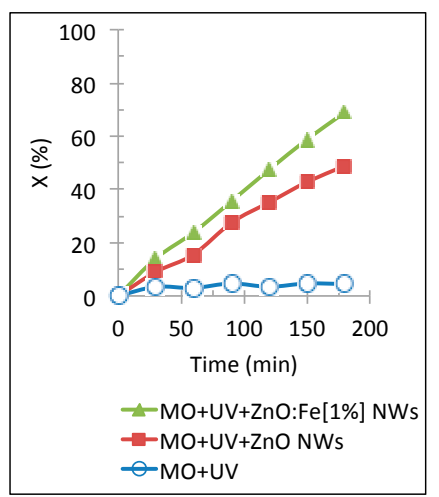

(b)

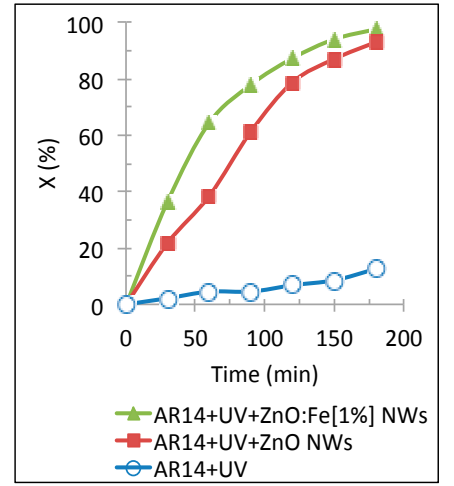

(c)

Figure 6. Photo-degradation rate evolution of the dye solutions: methylene blue (MB) (a); methyl orange (MO) (b); acid red 14 (AR14) (c) by photocatalysis in the presence of ZnO:Fe NWs, ZnO NWs and without $\mathrm{ZnO}$, respectively.

In fact, the Fe-doping of $\mathrm{ZnO} N W$ s allows the substitution of a few $\mathrm{Zn}$ atoms by Fe atoms, resulting in the creation of other energy levels above $\mathrm{VB}$ and below $\mathrm{CB}$ of $\mathrm{ZnO}$ (Figure 7) [18], leading to a reduction of the gap, then allowing the semiconductor to harvest more photons during the photocatalysis process. In addition, the introduction of iron leads to the formation of additional defects in the $\mathrm{ZnO}$ crystal lattice [19], which can become electron traps, reduces the recombination probability of the electron-hole pairs and leads to an acceleration of the formation of hydroxyl radicals. Thus, the photocatalytic efficiency of $\mathrm{ZnO}$ will be improved and, consequently, the photo-degradation rate of the dyes will be increased according to the reactions below:

$$
\begin{gathered}
\mathrm{Fe}^{3+}+\mathrm{e}^{-} \rightarrow \mathrm{Fe}^{2+} \\
\mathrm{Fe}^{2+}+\mathrm{O}_{2(\text { ads })} \rightarrow \mathrm{Fe}^{3+}+\mathrm{O}_{2}^{\bullet-} \\
\mathrm{Fe}^{3+}+\mathrm{h}^{+} \rightarrow \mathrm{Fe}^{4+} \\
\mathrm{Fe}^{4+}+\mathrm{OH}^{-} \rightarrow \mathrm{Fe}^{3+}+\mathrm{OH}^{\bullet}
\end{gathered}
$$

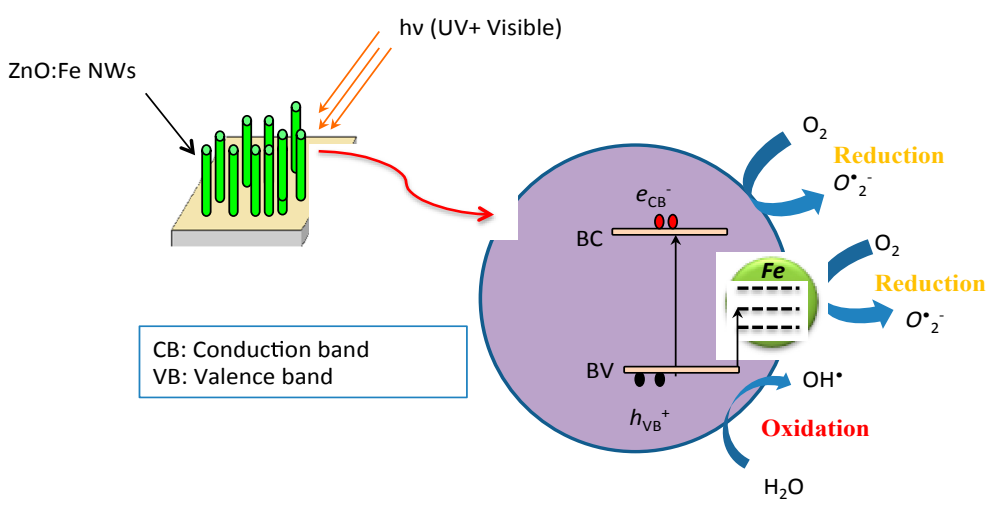

Figure 7. Diagram describing the photocatalytic mechanism of the Fe-doped ZnO NWs. 
In order to understand the trapping efficiency of charge carriers in doped $\mathrm{ZnO} \mathrm{NWs}$, PL measurements were performed on the undoped and doped samples. Figure 8a illustrates the PL emission spectra for undoped and Fe-doped ZnO NWs with an excitation wavelength of $325 \mathrm{~nm}$ (Laser He-Cd) (Model IK3101R-D, KIMMON K., Tokyo, Japan). It should be noted that the intensity of the laser on the sample is equal to $0.32 \mathrm{~W} / \mathrm{cm}^{2}$ and this value remained constant for all analyses carried out in this same experimental setup. We found that all obtained PL spectra are composed of two distinct emissions: A UV emission peak at $376 \mathrm{~nm}$ and a dominant and broad emission in the visible region ranging from green to red. The UV emission corresponding to the $\mathrm{ZnO}$ band gap transition is generally attributed to direct exciton recombination, where one of the excitons radically recombines to generate a photon; while the second emission in the visible range corresponds to defects and/or impurities in the structure and/or on the surface of $\mathrm{ZnO}$ nanostructures.

In the visible region, three main emissions can be distinguished:

- The green emission (G1), located in a wavelength range of $\sim 480-550 \mathrm{~nm}$. This emission has been associated with the simply ionized oxygen vacancies $\left(\mathrm{V}_{\mathrm{O}}^{\circ}\right)$, or the oxygen anti-sites $[20,21]$, or the zinc vacancies $\left(\mathrm{V}_{\mathrm{Zn}}^{\circ}\right)$ [22].

- The yellow-orange emission (G2) has wavelengths of $\sim 550-610 \mathrm{~nm}$, corresponds to the doubly ionized oxygen vacancies $\left(\mathrm{V}_{\mathrm{O}}^{\circ}\right)$ [23], and to the oxygen interstitials $\left(\mathrm{O}_{\mathrm{i}}\right)$ [21].

- Red emission (G3) ( 610-750 nm) was attributed to oxygen excess on the $\mathrm{ZnO}$ surface, which may be induced by post-annealing [24]. In addition, red emission can also be attributed to zinc interstitial $\left(\mathrm{Zn}_{\mathrm{i}}\right)[23,25]$.
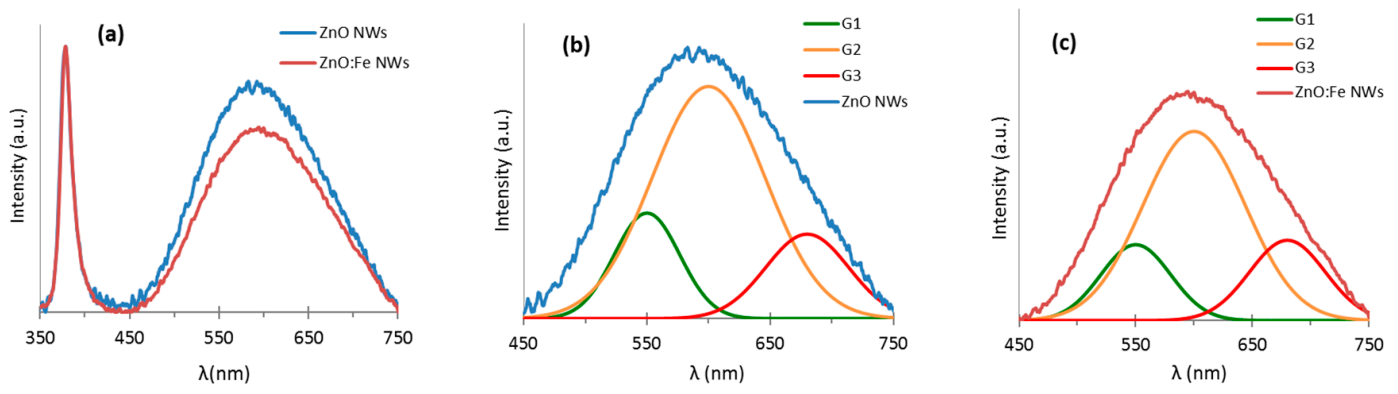

Figure 8. (a) Photoluminescence spectroscopy (PL) spectra of undoped $\mathrm{ZnO}$ NWs (blue curve) and Fe-doped ZnO NWs (red curve); (b,c) Visible emission band of PL spectrum and three Gaussian components G1 (green), G2 (yellow) and G3 (red) for ZnO NWs and ZnO:Fe NWs, respectively.

From Figure 8a, we can note that the $\mathrm{ZnO}$ NWs and ZnO:Fe NWs samples have the same characteristic peak corresponding to the transition of the $\mathrm{ZnO}$ gap energy (centered at $376 \mathrm{~nm}$ ) and also a wide emission in the visible range which represents various defects. We can notice that the intensity of PL relative to the emission of defects decreases with the introduction of iron into the $\mathrm{ZnO}$ NWs. This may be due to the fact that the excited electrons will react with the defects of the $\mathrm{ZnO}: \mathrm{Fe}$ NWs structures, thus resulting in a decrease in the emission relative to the defects. Cheng et al. [26] also carried out a PL analysis on $\mathrm{ZnO}$ films doped at different iron concentrations. They found that as the concentration of Fe in the films increases, the peak intensity of UV emission increases, while the visible emission intensity decreases. The result suggests that the crystal lattice of Fe-doped $\mathrm{ZnO}$ films exhibits fewer interstitial oxygen and oxygen vacancies compare to undoped $\mathrm{ZnO}$.

In order to make a comprehensive understanding of the PL evolution, the PL spectra were decomposed by using three Gaussian components: Green (G1), yellow-orange (G2) and red (G3) spectral region (Figure $8 b, c)$, usually suggested in literature and studied in our previous work [27]. After the deconvolution of the PL spectra on the visible emission related to the defects for the undoped and Fe-doped ZnO NWs (Figure 9), we observed a decrease in the intensity of both of G1 and G2 components, related to the oxygen vacancies and the oxygen interstitials, respectively. 
The PL spectrum decomposition allowed us to confirm that the electrons can also be trapped by the defects in the $\mathrm{ZnO}: \mathrm{Fe} \mathrm{NW}$ structure leading to a lower electron-hole pair recombination rate, and then increasing the photocatalytic activity, meaning the greater polluted water purification efficiency.

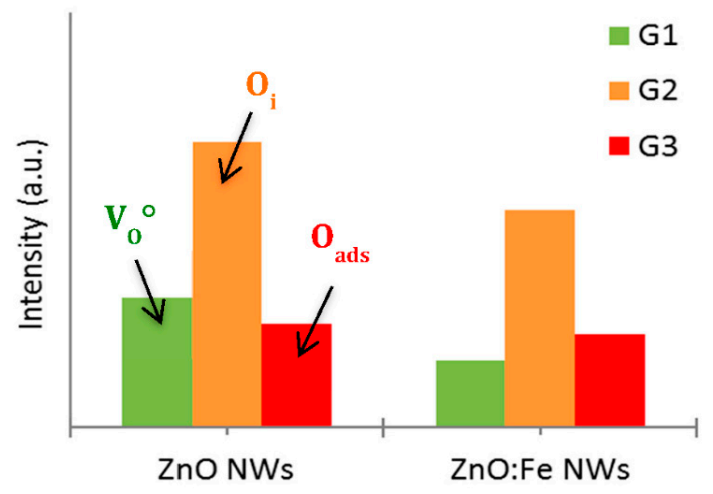

Figure 9. Intensity evolution of the various defect emissions in undoped and Fe-doped ZnO NWs.

\section{Conclusions}

In this study, the Fe-doped ZnO NWs has been studied for photocatalysis. Neither morphology nor microstructure of $\mathrm{ZnO} N W s$ has been changed by low concentration (1\%). Fe-doping is the growth solution for the hydrothermal synthesis method. In fact, doping can considerably increase the lifetime of charge carriers (electron-hole pairs) which play an essential role in the production of $\mathrm{OH}^{\bullet}$ radials necessary for the decomposition of the toxic organic compound in the polluted water into harmless compounds. In addition, iron doping allows the semiconductor to widen its light absorption spectral range (UV + Visible) during photocatalysis process and then to increase the defect rate in the $\mathrm{ZnO}$ crystal lattice. The electrons can be trapped in the Fe-doped $\mathrm{ZnO}$ NWs decreasing the electron-hole pair recombination possibility, leading to an improvement of the $\mathrm{ZnO}$ photocatalytic efficiency. We were able to improve the $\mathrm{MO}$ degradation rate by $20 \%$ with $\mathrm{ZnO}: \mathrm{Fe}$ NWs compared to the undoped $\mathrm{ZnO}$ NWs. PL analysis showed that the introduction of Fe into the $\mathrm{ZnO}$ structure leads to an overall decrease in visible emissions. This confirms that defects in the $\mathrm{ZnO}$ structure react with electrons, thereby reducing the electron-hole recombination probability.

Author Contributions: Yamina Ghozlane Habba and Martine Capochichi-Gnambodoe onceived and designed the experiments; Yamina Ghozlane Habba performed the experiments; Yamina Ghozlane Habba, Martine Capochichi-Gnambodoe and Yamin Leprince-Wang analyzed the data. Yamin Leprince-Wang supervised this research work and wrote the paper.

Conflicts of Interest: The authors declare no conflict of interest.

\section{References}

1. Huang, H.; Leung, D.Y.C.; Kwong, P.C.W.; Xiong, J.; Zhang, L. Enhanced photocatalytic degradation of methylene blue under vacuum ultraviolet irradiation. Catal. Today 2013, 201, 189-194. [CrossRef]

2. Saikia, L.; Bhuyana, D.; Saikia, M.; Malakar, B.; Dutta, D.K.; Sengupta, P. Photocatalytic performance of ZnO nanomaterials for self-sensitized degradation of malachite green dye under solar light. Appl. Catal. A 2015, 490, 42-49. [CrossRef]

3. Wu, J.J.; Tseng, C.H. Photocatalytic properties of nc-Au/ZnO nanorod composites. Appl. Catal. B 2006, 66, 51-57. [CrossRef]

4. Wang, Y.W.; Zhang, L.Z.; Deng, K.J.; Chen, X.; Zou, Z.G. Low temperature synthesis and photocatalytic activity of rutile $\mathrm{TiO}_{2}$ nanorod superstructures. J. Phys. Chem. C 2007, 111, 2709-2714. [CrossRef]

5. Reynolds, D.C.; Look, D.C.; Jogai, B.; Hoelscher, J.E.; Sherriff, R.E.; Harris, M.T.; Callahan, M.J. Time-resolved photoluminescence lifetime measurements of the $\Gamma_{5}$ and $\Gamma_{6}$ free excitons in ZnO. J. Appl. Phys. 2000, 88, 2152-2153. [CrossRef] 
6. Ryu, J.; Choi, W. Substrate-specific photocatalytic activities of $\mathrm{TiO}_{2}$ and multiactivity test for water treatment application. Environ. Sci. Technol. 2008, 42, 294-300. [CrossRef] [PubMed]

7. Zou, Z.; Ye, J.; Sayama, K.; Arakawa, H. Direct splitting of water under visible light irradiation with an oxide semiconductor photocatalyst. Nature 2001, 414, 625-627. [CrossRef] [PubMed]

8. Asahi, R.; Morikawa, T.; Ohwaki, T.; Aoki, K.; Taga, Y. Visible-light photocatalysis in nitrogen-doped titanium oxides. Science 2001, 293, 269-271. [CrossRef] [PubMed]

9. Anpo, M.; Takeuchi, M. The design and development of highly reactive titanium oxide photocatalysts operating under visible light irradiation. J. Catal. 2003, 216, 505-516. [CrossRef]

10. Su, X.; Jia, Y.; Liu, X.; Wang, J.; Xu, J.; He, X.; Fu, C.; Liu, S. Preparation, dielectric property and infrared emissivity of $\mathrm{Fe}$-doped $\mathrm{ZnO}$ powder by coprecipitation method at various reaction time. Ceram. Int. 2014, 40, 5307-5311. [CrossRef]

11. Zhang, K.Z.; Lin, B.Z.; Chen, Y.L.; Xu, B.H.; Pian, X.T.; Kuang, J.D.; Li, B. Fe-doped and ZnO-pillared titanates as visible-light-driven photocatalysts. J. Colloid Interface Sci. 2011, 358, 360-368. [CrossRef] [PubMed]

12. Qiu, X.Q.; Li, L.P.; Zheng, J.; Liu, J.J.; Sun, X.F.; Li, G.S. Origin of the enhanced photocatalytic activities of semiconductors: A case study of $\mathrm{ZnO}$ doped with $\mathrm{Mg}^{2+}$. J. Phys. Chem. C 2008, 112, 12242-12248. [CrossRef]

13. Cao, Y.Q.; He, T.; Chen, Y.M.; Cao, Y.A. Fabrication of rutile TiO2-Sn/Anatase $\mathrm{TiO} 2-\mathrm{N}$ heterostructure and its application in visible-light photocatalysis. J. Phys. Chem. C 2010, 114, 3627-3633. [CrossRef]

14. Habba, Y.G.; Capochichi-Gnambodoe, M.; Serairi, L.; Leprince-Wang, Y. Enhanced photocatalytic activity of $\mathrm{ZnO}$ nanostructure for water purification. Phys. Status Solidi B 2016, 253, 1480-1484. [CrossRef]

15. Tauc, J. Optical properties and electronic structure of amorphous Ge and Si. Mater. Res. Bull. 1968, 3, 37-46. [CrossRef]

16. Bhat, S.V.; Deepak, F.L. Tuning the bandgap of $\mathrm{ZnO}$ by substitution with $\mathrm{Mn}^{2+}, \mathrm{Co}^{2+}$ and $\mathrm{Ni}^{2+}$. Solid State Commun. 2005, 135, 345-347. [CrossRef]

17. Dhiman, P.; Chand, J.; Kumar, A.; Kotnala, R.K.; Batoo, M.K.; Singh, M. Synthesis and characterization of novel Fe@ZnO nanosystem. J. Alloys Compd. 2013, 578, 235-241. [CrossRef]

18. Liu, M.; Qiu, X.; Miyauchi, M.; Hashimoto, K. Energy-level matching of Fe(III) ions grafted at surface and doped in bulk for efficient visible-light photocatalysts. J. Am. Chem. Soc. 2013, 135, 10064-10072. [CrossRef] [PubMed]

19. Kumar, K.; Chitkara, M.; Sandhu, I.S.; Mehta, D.; Kumar, S. Photocatalytic optical and magnetic properties of Fe-doped ZnO nanoparticles prepared by chemical route. J. Alloys Compd. 2014, 588, 681-689. [CrossRef]

20. Studenikin, S.A.; Golego, N.; Cocivera, M. Fabrication of green and orange photoluminescent, undoped ZnO films using spray pyrolysis. J. Appl. Phys. 1998, 84, 2287-2294. [CrossRef]

21. Li, D.; Leung, Y.H.; Djurišić, A.B.; Liu, Z.T.; Xie, M.H.; Shi, S.L.; Xu, S.J. Different origins of visible luminescence in $\mathrm{ZnO}$ nanostructures fabricated by the chemical and evaporation methods. Appl. Phys. Lett. 2004, 85, 1601-1605. [CrossRef]

22. Kwok, W.M.; Djurišić, A.B.; Leung, Y.H.; Chan, W.K.; Phillips, D.L. Time-resolved photoluminescence from ZnO nanostructures. Appl. Phys. Lett. 2005, 87, 223111-223114. [CrossRef]

23. Panigrahy, B.; Aslam, M.; Misra, D.S.; Ghosh, M.; Bahadur, D. Defect-related emissions and magnetization properties of ZnO nanorods. Adv. Funct. Mater. 2010, 20, 1161-1165. [CrossRef]

24. Cross, R.B.M.; De Souza, M.M.; Sankara Narayanan, E.M. A low temperature combination method for the production of ZnO nanowires. Nanotechnology 2005, 16, 2188-2192. [CrossRef] [PubMed]

25. Gomi, M.; Oohira, N.; Ozaki, K.; Koyano, M. Photoluminescent and structural properties of precipitated ZnO fine particles. Jpn. J. Appl. Phys. 2003, 42, 481-485. [CrossRef]

26. Cheng, W.; Ma, X. Structural, optical and magnetic properties of Fe-doped ZnO. J. Phys. Conf. Ser. 2009, 152, 012039. [CrossRef]

27. Chevalier-César, C.; Capochichi-Gnambodoe, M.; Leprince-Wang, Y. Growth mechanism studies of ZnO nanowire arrays via hydrothermal method. Appl. Phys. A 2014, 115, 953-960. [CrossRef]

(C) 2017 by the authors. Licensee MDPI, Basel, Switzerland. This article is an open access article distributed under the terms and conditions of the Creative Commons Attribution (CC BY) license (http:/ / creativecommons.org/licenses/by/4.0/). 